\title{
Mass spectrometric analysis of additives in polymer extracts by desorption chemical ionization and collisional induced dissociation with $\mathrm{B} / \mathrm{E}$ linked scanning
}

\author{
C.G. Juo, S.W. Chen, G.R. Her * \\ Department of Chemistry, National Taiwan University, Taipei, Taiwan
}

Received 9 September 1994; revised 17 February 1995; accepted 29 March 1995

\begin{abstract}
Desorption chemical ionization in combination with collisional induced dissociation and B/E linked scan proved to be a viable method for identifying additives in polyethylene extracts by mass spectrometry. In comparison with fast atom bombardment (FAB), much less fragmentation was observed with desorption chemical ionization (DCI) using ammonia as reagent gas. Furthermore, most likely due to the "matrix effect", not all the additives in the extracts were detected by FAB. The softness and the lack of matrix effect make ammonia DCI a better ionization technique than FAB for the analysis of additives directly from the extracts. Most likely due to higher collision energy, product ion mass spectra acquired with a double focusing mass spectrometer provided more structural information than the spectra obtained with a triple quadrupole mass spectrometer. Besides contamination from the seals of the supercritical fluid extractor, high and low density polyethylenes extracted with supercritical carbon dioxide produced similar results as with toluene.
\end{abstract}

Keywords: Mass spectrometry; Desorption chemical ionization; Collisional induced dissociation; Polyethylene; Polymers; Supercritical fluid extraction

\section{Introduction}

The range of applications for polymeric materials is extending at an amazing rate and the number of additives available to modify polymer properties is increasing proportionately. Reliable and rapid analytical methods are often needed for the identification of unknown additives in polymers and/or monitor-

\footnotetext{
* Corresponding author.
}

ing the stability of additives during processing and service. Successful analytical methodologies must not only distinguish between the number of components but also provide characteristic structural information about each additive. Direct spectroscopic methods, such as ultraviolet absorption, infrared [1], fluorescence, phosphorescence, and X-ray fluorescence [2] spectroscopy, have been reported. In some cases they are useful, but generally they suffer from interferences. A more desirable approach requires extraction of the additives following by off- or on-line chromatographic separation and spectroscopic identi- 
<smiles>CN(C)c1nc(NC(C)(C)C)nc(N(C)C2CC(C)(C)NC(C)(C(C)(C)C)C2)n1</smiles>

a. Chimassorb<smiles>CN1C(Cc2cc(C(C)(C)C)c(O)c(C(C)(C)C)c2)CC(OC(=O)C(C)(C)CC(=O)OC2CC(C)(C)N(C)C(C)(C)C2)CC1(C)C</smiles>

b. Tinuvin 144<smiles>CCOC(=O)CCc1cc(C(C)(C)C)c(O)c(C(C)(C)C)c1</smiles>

e. Irganox 1010<smiles>CC(CCO)COC(=O)CCc1cc(C(C)(C)C)c(O)c(C(C)(C)C)c1</smiles>

f.<smiles>CCCCCCCCCCC(=O)OCCCC(=O)OC</smiles>

\section{g. DSTDP}<smiles>CN(C)C(=O)CCCC(=O)NCCCCCc1cc(C(C)(C)C)c(O)c(C(C)(C)C)c1</smiles>

c. Irganox 1098<smiles>CCCCCCCCCCCC(=O)OCCc1cc(C(C)(C)C)c(O)c(C(C)(C)C)c1</smiles>

h. Irganox 1076<smiles>CC(C)(C)c1ccc(OP(=O)(Oc2ccc(C(F)(F)F)cc2C(C)(C)C)Oc2ccc(C(F)(F)F)cc2C(C)(C)C)c(C(C)(C)C)c1</smiles>

d. Oxidized Naugard 524<smiles>Cc1c(Cc2cc(C(C)(C)C)c(O)c(C(C)(C)C)c2)c(C)c(Cc2cc(C(C)(C)C)c(O)c(C(C)(C)C)c2)c(C)c1Cc1cc(C(C)(C)C)c(O)c(C(C)(C)C)c1</smiles>

i. Ionox 330

Fig. 1. Structures and trivial names of additives presented in this work. 
fication [3-15]. These methods are generally time consuming.

Mass spectrometry (MS) with the advantages of sensitivity and large dynamic range has routinely been employed for additives analysis [16-19]. Moving toward higher molecular weight additives with less volatility [20], conventional MS techniques such as electron ionization (EI), chemical ionization (CI) and gas chromatography (GC)-MS are not more suitable for these additives. Thus soft ionization techniques, such as field ionization (FI) $[16,17]$, field desorption (FD) [16], fast atom bombardment (FAB) $[21,22]$, desorption chemical ionization (DCI) [23] and laser desorption (LD) $[22,24,25]$ all have been investigated for their utility in the analysis of high molecular weight additives. Among these ionization techniques, FAB and DCI are considered the two most popular methods. FAB is popular for its eases of operation and ability to analyze high molecular weight compounds whereas DCI is known for the specificity provided by choosing reagent gases with different proton affinities.

Concurrent with the development of the soft ionization technique has been the development of tandem mass spectrometry. One of the major applications of a tandem mass spectrometer lies in its coupling with collisional induced dissociation (CID) in the analysis of mixture without prior chromatographic separation. Among the many different type of instruments, a triple quadrupole mass spectrometer and a double focusing mass spectrometer are the two most popular instruments used in product ion analysis. A previous study using a triple quadrupole mass spectrometer has shown great specificity and potential for the identification of additives directly from polyethylene extracts [23]. However, for compounds with a more rigid structure, such as hindered amines and phosphates, the product ion mass spectra did not produce structurally characteristic fragments for a clear structure assignment. The lack of structurally characteristic fragment ions is likely to be due to the low collision energy associated with triple quadrupole instrument.

In this paper, the selection of ionization technique, the extraction of additives with an organic solvent or supercritical fluid, and the potential of using a high collision energy in the analysis of polymer additives are reported.

\section{Experimental}

\subsection{Chemicals}

Additive standards were kindly provided by Ciba-Geigy (Taiwan). Oxidized Naugard 524 was prepared by oxidation of Naugard 524 with hydrogen peroxide. The structures and trivial names of the additives presented in this work are shown in Fig. 1. Polyethylene samples were obtained from local suppliers.

\subsection{Polymer extracts}

A weighed polymer sample (ca. $1 \mathrm{~g}$ ) was refluxed with $100 \mathrm{ml}$ of toluene in a $250-\mathrm{ml}$ round-bottomed flask for $3 \mathrm{~h}$. After cooling, $20 \mathrm{ml}$ of ethanol was added to precipitate low molecular weight polymer. The extract solutions were filtered, dried and reconstituted in methylene chloride before mass spectrometric analysis.

Supercritical fluid extraction (SFE) was performed on a ca. $0.2 \mathrm{~g}$ sample that had been weighed into the extraction cell. The extraction was operated with a model 100DX syringe pump and an SFX 2-10 extractor (Isco). The samples were extracted with $600 \mathrm{~atm} \mathrm{CO}_{2}$ at $40^{\circ} \mathrm{C}$. The pressure was held for $30 \mathrm{~min}$ and $5 \mathrm{~h}$ for low and high density polyethylenes, respectively. After extraction, the extracts were collected by inserting the end of the restrictor into a $13 \times 100 \mathrm{~mm}$ glass tube containing ca. $6 \mathrm{ml}$ of methylene chloride.

\subsection{Mass spectrometry}

Fast atom bombardment was performed on a Jeol SX-102A double focusing mass spectrometer of reversed geometry. The FAB gun was operated at $6 \mathrm{kV}$ using xenon as the ionizing gas. A $1 \mu$ l sample solution was mixed with $1 \mu$ l of matrix (3-nitrobenzyl alcohol) on the FAB probe tip for subsequent analysis. Desorption chemical ionization was performed on a Finnigan TSQ-46C triple quadrupole mass spectrometer (Finnigan MAT, CA) and a Jeol SX-102A double focusing mass spectrometer. Ammonia (San-Fu, Hsinchu, Taiwan) was chosen as the reagent gas. The sample was air-dried on a platinum emitter; the emitter was heated at $0.25 \mathrm{~A} \mathrm{~min}^{-1}$. 
Argon and helium were used as the collision gas in the triple quadrupole and double focusing instruments, respectively. The pressure of the collision gas was adjusted to decrease the ion beam to $30 \%$ of its usual value. $B / E$ linked scan and mass analyzed ion kinetic energy spectra were acquired at a scan rate of $20 \mathrm{~s}$ per scan. The mass scale in the linked scan mode was calibrated with a mixture of alkali halides [26].

\section{Results and discussion}

\subsection{Method of ionization}

It is to be expected that there is more than one additive in the polymer extract because different additives are needed for modifying polymer properties. An ideal ionization technique for the analysis of these additives by MS-MS should produce protonated and/or ammoniated molecular ions with little or no fragmentation for each additive in the extract. The structure of the additives can then be further investigated with collisional induced dissociation of the protonated or ammoniated molecular ions. Although FAB was the most popular soft ionization method for the analysis of low volatility and medium molecular weight compounds, it was somewhat unfortunate to see that many additives fragmented quite extensively under FAB. The observation of molecular ion as well as many fragment ions for each additive made the determination of the number of additives in the extract difficult if not impossible. In addition, more likely due to the popular "matrix effect" [27], not all additives in polymer extracts were detected under FAB. These two problems could be alleviated greatly with DCI using ammonia as the reagent gas. Because of its high proton affinity, ammonia frequently produced very simple $\mathrm{DCI}$ mass spectra consisting of $(\mathrm{M}+\mathrm{H})^{+}$and / or $\left(\mathrm{M}+\mathrm{NH}_{4}\right)^{+}$ ions with very little fragmentation. Furthermore, the signals due to the low molecular weight polyethylene coextracted with the additives were greatly decreased because of the low proton affinity of polyethylene. In recent years, demands have increased for polymer products with higher durability. One solution to this problem is to use polymeric stabilizers of higher molecular weight in order to inhibit their loss during processing and use. While FAB is, in general, superior to DCI for the analysis of high molecular weight compounds, the present results for the analysis of additives with molecular weight $>2000$ amu suggested that DCI was adequate for the analysis of these additives. Moreover, the quality of the spectra

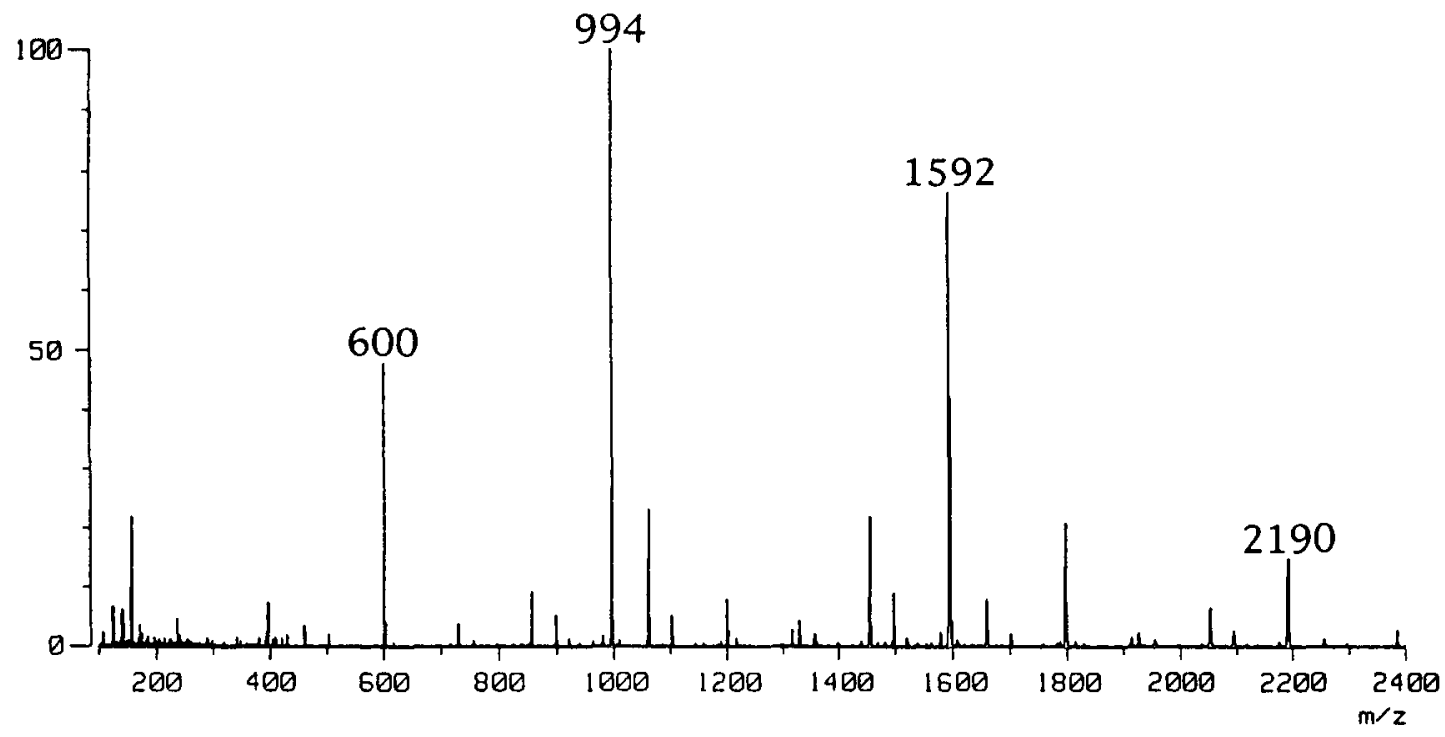

Fig. 2. Ammonia DCI mass spectrum of Chimassorb 944. 

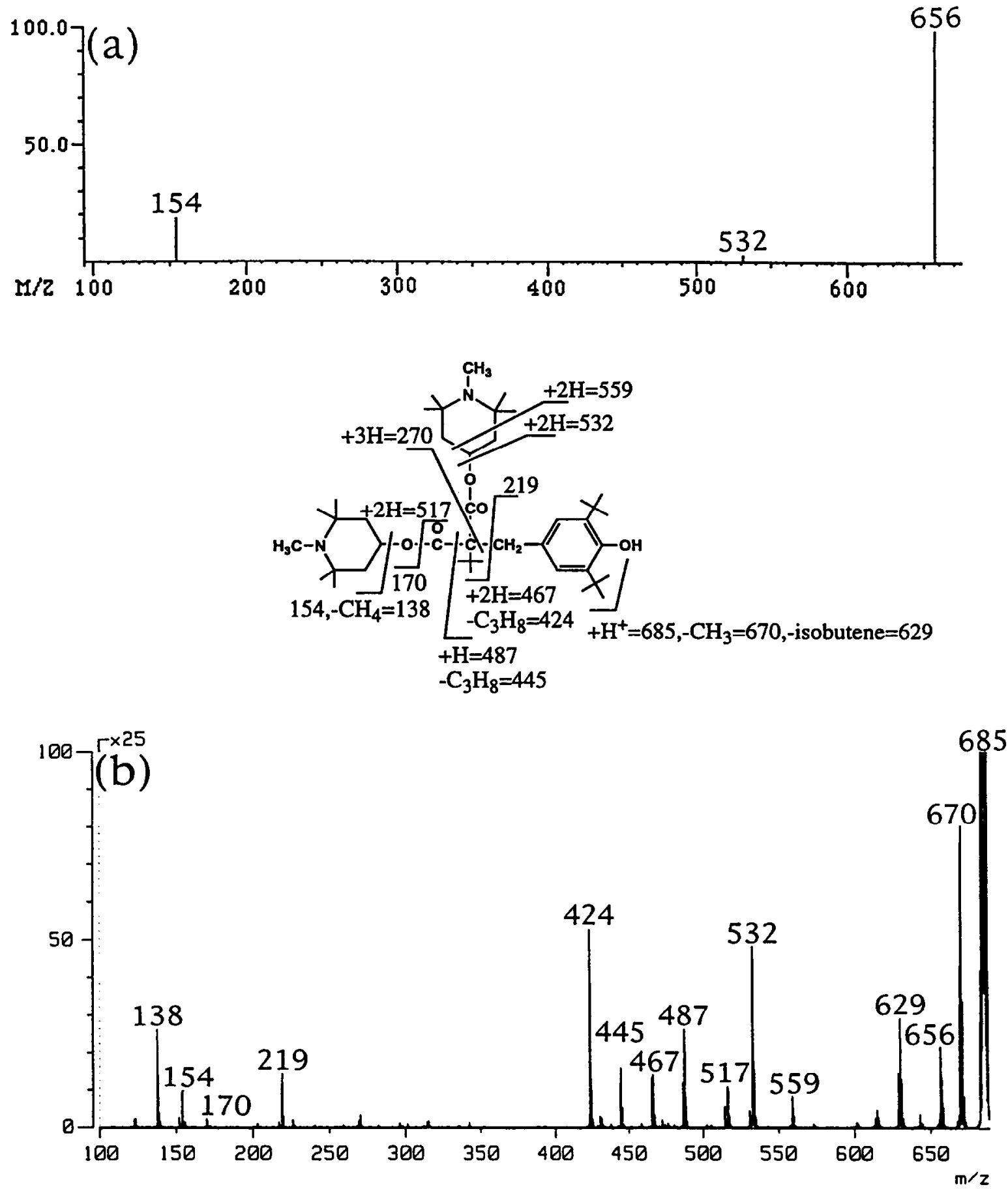

Fig. 3. (a) Low collision energy; (b) high collision energy product ion mass spectrum of the $(M+H)^{+}$ion $(m / z$ 685) of Tinuvin 144 . 

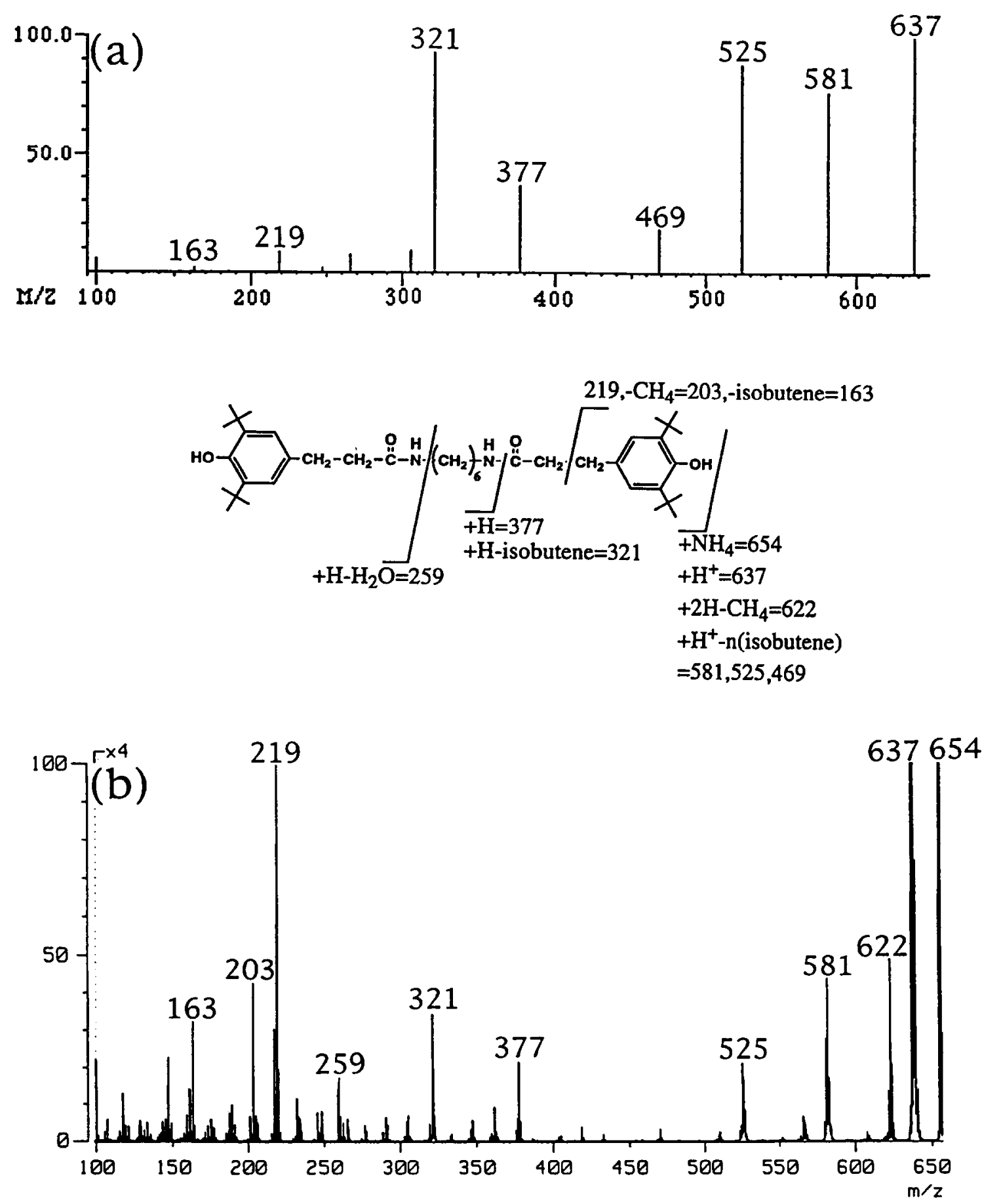

Fig. 4. (a) Low collision energy; (b) high collision energy product ion mass spectrum of the $\left(\mathrm{M}+\mathrm{NH}_{4}\right)^{+}$ion $(m / z$ 654) of Irganox 1098 . 

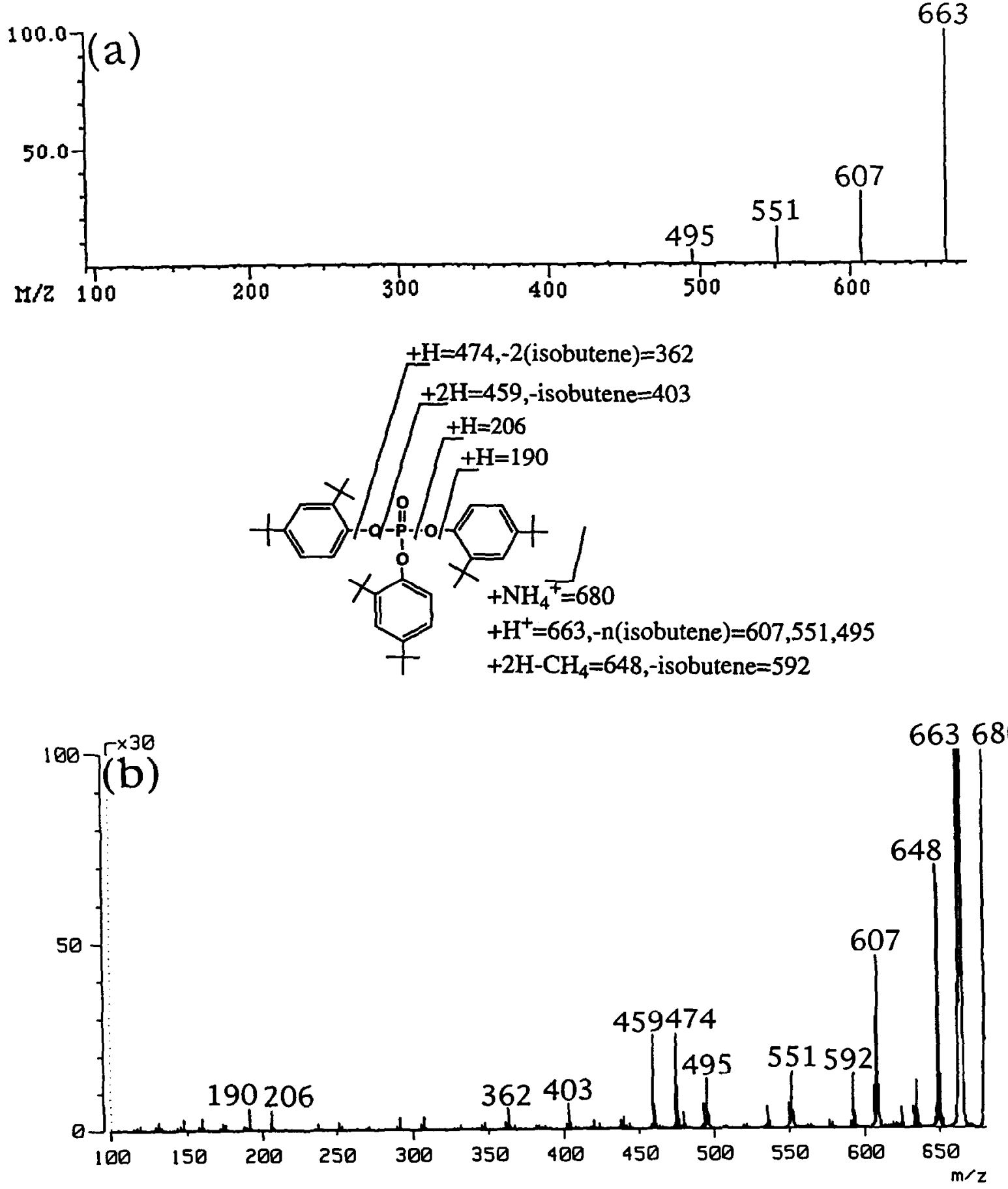

Fig. 5. (a) Low collision energy; (b) high collision energy product ion mass spectrum of the $\left(\mathrm{M}+\mathrm{NH}_{4}\right)^{+}$ion $(m / z 680)$ of oxidized Naugard 524. 


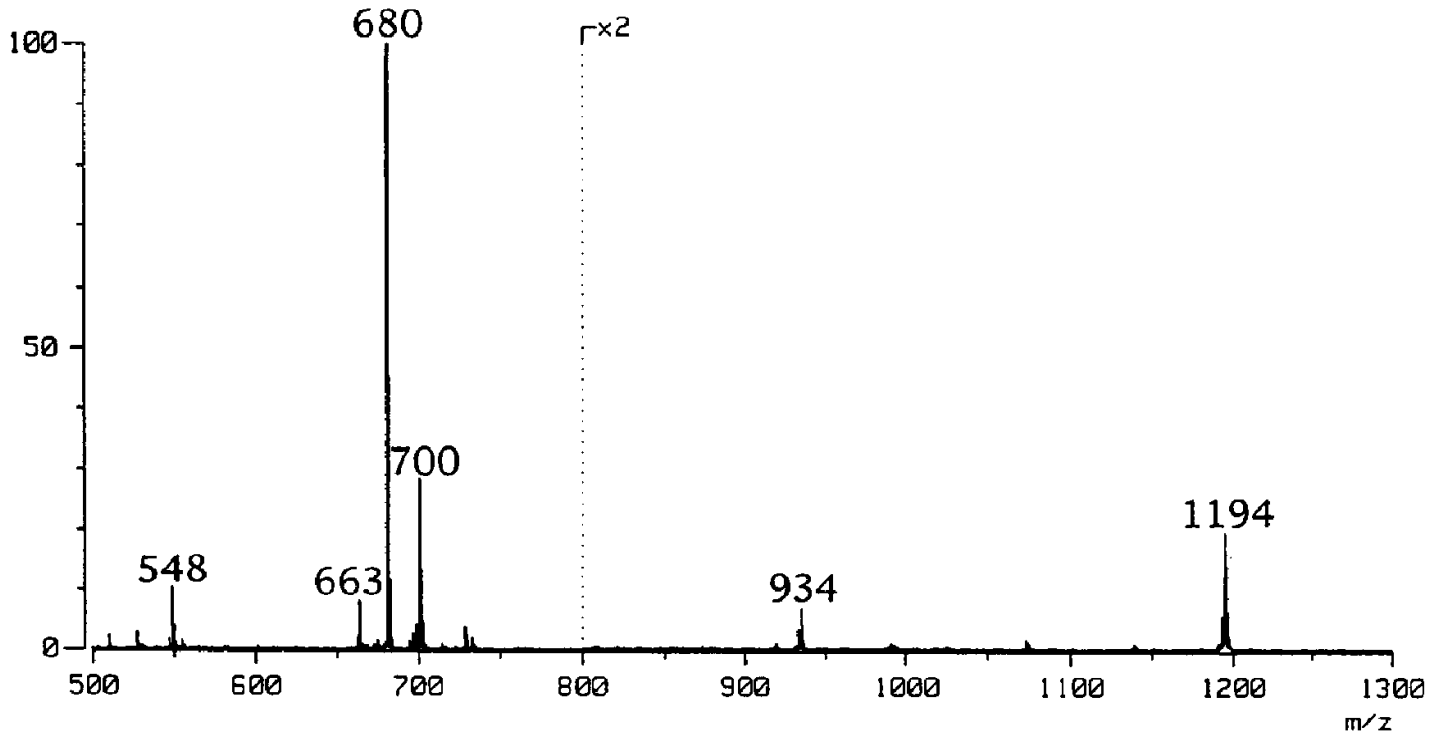

Fig. 6. Ammonia DCI mass spectrum of a high-density polyethylene extract.

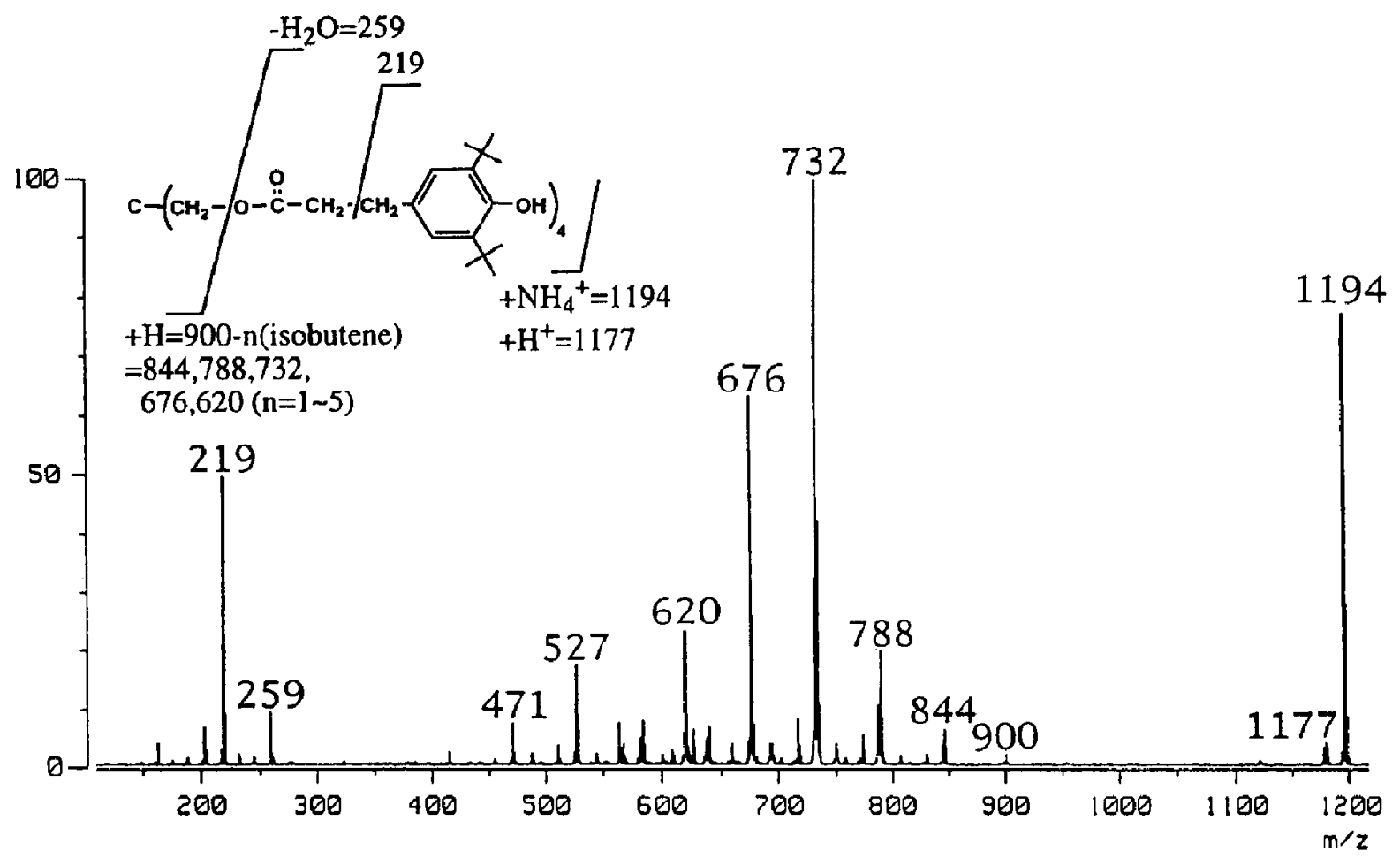

Fig. 7. Product ion mass spectrum of the $\left(\mathbf{M}+\mathbf{N H}_{4}\right)^{+}$ion $(m / z 1194)$ of Irganox 1010 . 
was better than the spectra obtained with FAB. The ammonia DCI mass spectrum of a high molecular weight additive, Chimassorb 944, is shown in Fig. 2.
The $m / z 600$ ion, is the molecular ion of the monomer, the base peak at $m / z 994$ corresponds to the dimer losing one of the triazine groups. A series
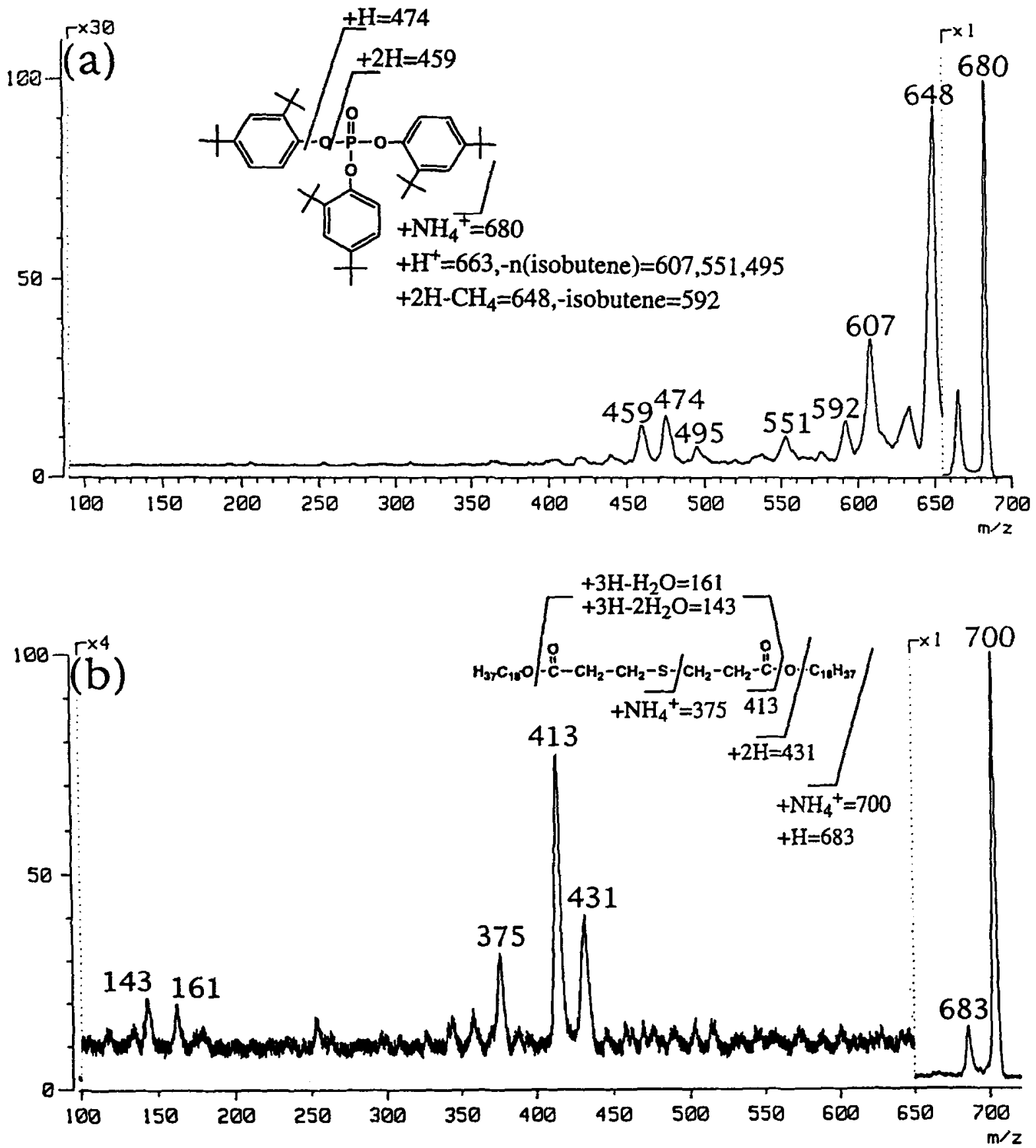

Fig. 8. MIKES spectrum of (a) the $m / z 680$ ion; (b) the $m / z 700$ ion. 
of ions with mass interval of a repeating unit were also observed $(994,1592,2190)$.

\subsection{Product ion mass spectra of additives}

The fragmentation of a gas phase ion is closely associated with the internal energy of the ion. In the increasing of internal energy with CID, the accelera- tion voltage of the mass spectrometer plays an important role because the maximum energy which can be converted into internal energy is proportional to the translational energy of the precursor ion. In comparison with the quadrupole instrument, the sector instrument has a much higher acceleration energy (3-10 kV vs. 1-250 V) and thus it can produce more structural information. The present study with
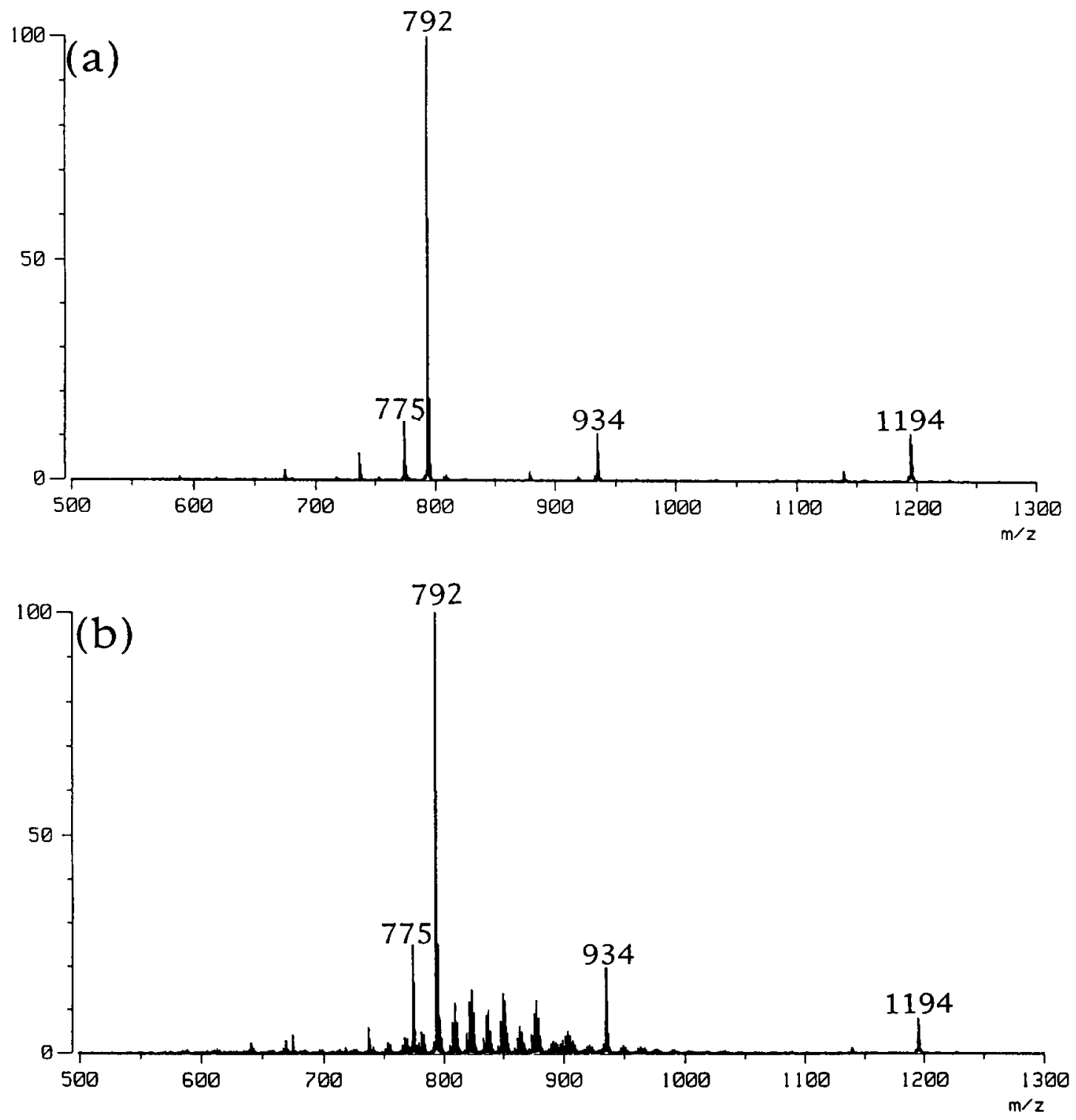

Fig. 9. Ammonia DCI mass spectrum of the second high-density polyethylene extract (a) with toluene; (b) with supercritical $\mathrm{CO}_{2}$. 
more than twenty additives showed that high energy CID always produced more fragments than low energy CID. The magnitude of the difference was mainly dependent on the structure of the additives. For instance, the difference between high and low energy CID for hindered amines, as exemplified with Tinuvin 144 (Fig. 3), was much more significant than the difference observed for phenolic antioxidants (Fig. 4).

Phosphite antioxidants are generally considered to be secondary antioxidants; their function is to control polymer molecular weight and color. Phosphite stabilizers react with hydroperoxide, peroxy radicals, alkoxy radicals and carbonyl moieties, and are oxidized to phosphate thus losing their activities. Thus both phosphite and phosphate are usually present in the polymer products. Our previous study of the oxidized phosphite antioxidant, Naugard 524 and Santostab PEPQ, with a triple quadrupole mass spectrometer showed only the sequential loss of isobutene from the molecules and thus offered little structural information [23]. It was good to see, however, that on high energy CID, structurally characteristic fragments resulting from the cleavage of $\mathrm{O}-\mathrm{P}(\mathrm{m} / \mathrm{z}$ 459) and C-OP $(m / z$ 474) bonds were observed (Fig. 5). These ions provided clear evidence for the presence of a di-tertiary butyl phenolic group.

\subsection{Polyethylene extracted with toluene}

Several low and high density polyethylene products were extracted with toluene and analyzed directly by DCI and CID. The ammonia DCI mass spectrum of a high density black pipe sample is shown in Fig. 6. $\left(\mathrm{M}+\mathrm{NH}_{4}\right)^{+}$and /or $(\mathrm{M}+\mathrm{H})^{+}$ion pairs at $m / z 548,680 / 663,700,934$, and 1194 for several additives were clearly distinguishable. The product ion spectrum of the $\mathrm{m} / z 1194$ ion (Fig. 7) suggested that it was a phenolic antioxidant -Irganox 1010. The product ion spectrum of the $\mathrm{m} / z 934$ ion showed a very similar fragmentation pattern to that of $m / z 1194$ and thus it was assigned as the $(\mathrm{M}+$ $\left.\mathrm{NH}_{4}\right)^{+}$ion of a compound with the structure of compound $f$ (Fig. 1). The origin of this compound is not clear. It was more likely to be a real compound in the extract because the $m / z 934$ ion was not observed as a significant ion in the standard DCI spectrum of Irganox 1010. This compound could be produced during processing, use or even solvent extraction. A linked scan with constant $B / E$ does not have the necessary precursor ion resolution for the differentiation of $\mathrm{m} / z 680$ and 700 ions. Therefore, mass analyzed ion kinetic energy spectra (MIKES) were acquired (Fig. 8) and the $m / z 680$ and 700 ions were assigned as the $\left(\mathrm{M}+\mathrm{NH}_{4}\right)^{+}$ions of a phosphate-oxidized Naugard 524 and a thioester antioxidant-DSTDP, respectively. Finally, the ion at $m / z 548$ (Fig. 6) was assigned as the $\left(\mathrm{M}+\mathrm{NH}_{4}\right)^{+}$ ions of another antioxidant -Irganox 1076. A black pipe sample from another manufacturer was also analyzed by this technique. Based on the DCI spectrum (Fig. 9a) and product ion spectra (not shown), the additives at $m / z 792$ and 1194 were assigned as Ionox 330 (MW 774) and Irganox 1010, respectively. The ion at $m / z 934$, previously assigned as compound $f$, was also observed in this sample. The analysis of these two black pipe samples indicated that even with a very similar application, the use of additives could be quite different from one to the other.

\subsection{Polyethylene extracted with a supercritical fluid}

Supercritical fluid extraction has emerged as a rapid and efficient method for extracting organic compounds from various matrices. The primary advantages of SFE over liquid phase extraction are that mass transfer of analytes occurs quickly and efficiently and produces no toxic solvent waste $[3,10,13,14,28,29]$. To date, carbon dioxide is the most common supercritical fluid used and it has been shown to be able to extract antioxidants from flaked polyethylene samples with less interference from low molecular weight polyethylene [10]. All the samples studied by solvent extraction were also extracted with supercritical carbon dioxide. The results showed that additives in low density tarp samples could easily be extracted with supercritical $\mathrm{CO}_{2}$, whereas additives in some of the high density polyethylenes could not be extracted even with $3 \%$ methanol as modificr. The DCI spectra with liquid phase and supercritical fluid extraction were, in general, very similar. A typical example is shown in Fig. 9b. Besides the cluster of ions around $\mathrm{m} / \mathrm{z} 850$ which were determined as coming from the seals of the extractor, the DCI spectrum after SFE was very 
similar to the spectrum obtained after solvent extraction (Fig. 9a). The ion at $m / z 934$ was also observed in Fig. $9 \mathrm{~b}$. The temperatures used in supercritical fluid and solvent extraction were $40^{\circ} \mathrm{C}$ and $110^{\circ} \mathrm{C}$, respectively, so the detection of this ion in both spectra suggested that pyrolysis during extraction was not a major cause for the observation of the $m / z 934$ ion.

\section{References}

[1] H.L. Spell and R.D. Eddy, Anal. Chem., 32 (1960) 1811.

[2] G.R. Goe, Soc. Plast. Eng. Tech., 23 (1977) 496.

[3] R.C. Wieboldt, K.D. Kempfert and D.L. Dalrymple, Appl. Spectrosc., 44 (1990) 1028.

[4] D.A. Wheeler, Talanta, 15 (1968) 1315.

[5] A.M. Wims and S.J. Swarin, J. Appl. Polym. Sci., 19 (1975) 1243.

[6] J.F. Schabron and L.E. Fenska, Anal. Chem., 52 (1980) 1411.

[7] M.W. Raynor, K.D. Bartle, I.L. Davies, A. Williams, A.A. Clifford, J.M. Chalmers and B.W. Cook, Anal. Chem., 60 (1988) 427.

[8] D. Dilettato, P.J. Arpino, K. Nguyen and A. Bruchet, High Resolut. Chromatogr., 14 (1991) 335.

[9] J.D. Vargo and K.L. Olson, Anal. Chem., 57 (1985) 672.

[10] M. Ashraf Khorassani and J.M. Levy, High Resolut. Chromatogr., 13 (1990) 742.

[11] P.J. Arpino, D. Dilettato, K. Nguyen and A. Bruchet, High Resolut. Chromatogr., 13 (1990) 5.
[12] B.E. Berg, D.R. Hegna, N. Orlien and T. Greibrokk, Chromatographia, 37 (1993) 271.

[13] J.W. Oudsema and C.F. Poole, High Resolut. Chromatogr., 16 (1993) 198.

[14] T.P. Hunt, C.J. Dowel and G. Greenway, Analyst, 116 (1991) 1299.

[15] J.D. Vargo and K.L. Olson, J. Chromatogr., 353 (1986) 215.

[16] R.P. Lattimer, R.E. Harris, C.K. Rhee and H.-R. Schulten, Anal. Chem., 58 (1986) 3188.

[17] R.P. Lattimer, J. Anal. Appl. Pyrol., 26 (1993) 65.

[18] T. Yoshikawa, K. Ushimi, K. Kimura and M. Tamura, J. Appl. Polym. Sci., 15 (1971) 2065.

[19] P. Rudewicz and B. Munson, Anal. Chem., 58 (1986) 358.

[20] M. Minagawa, Polymer Degradation and Stability, 25 (1989) 121.

[21] T.L. Riley, T.J. Prater, J.L. Gerlock, J.E. de Vries and D. Schuetzle, Anal. Chem., 56 (1984) 2145.

[22] C.L. Johlman, C.L. Wilkins, J.D. Hogan, T.L. Donovan, D.A. Laude Jr. and M.-J. Youssefi, Anal. Chem., 62 (1990) 1167.

[23] S.W. Chen and G.R. Her, Appl. Spectrosc., 47 (1993) 844.

[24] B. Asamoto, J.R. Young and R.J. Citerin, Anal. Chem., 62 (1990) 61.

[25] X. Xiang, J. Dahlgren, W.P. Enlow and A.G. Marshall, Anal. Chem., 64 (1992) 2862.

[26] K. Sato, T. Asada, M. Ishihara, F. Kunihiro, Y. Kammei, E. Kubota, C.E. Costello, S.A. Martin, H.A. Scoble and K. Biemann, Anal. Chem., 59 (1987) 1652.

[27] E.D. Pauw, Methods Enzymol., 193 (1990) 202.

[28] S.B. Hawthorne, Anal. Chem., 62 (1990) 633A.

[29] J.J. Langenfeld, S.B. Hawthorne, D.J. Miller and J. Pawliszyn, Anal. Chem., 65 (1993) 338. 